Article

\title{
Complete Chloroplast Genomes from Sanguisorba: Identity and Variation Among Four Species
}

\author{
Xiang-Xiao Meng ${ }^{1,+}$, Yan-Fang Xian ${ }^{2,+}$, Li Xiang ${ }^{1}$, Dong Zhang ${ }^{1}$, Yu-Hua Shi ${ }^{1}$, Ming-Li Wu ${ }^{1}$, \\ Gang-Qiang Dong ${ }^{3}$ (D), Siu-Po Ip ${ }^{2}$, Zhi-Xiu Lin ${ }^{2}$, Lan $\mathrm{Wu}^{1,2, *}$ and Wei Sun ${ }^{1, *}$ \\ 1 Key Laboratory of Beijing for Identification and Safety Evaluation of Chinese Medicine, Institute of Chinese \\ Materia Medica, China Academy of Chinese Medical Sciences, Beijing 100700, China; \\ xxmeng@icmm.ac.cn (X.-X.M.); lxiang@icmm.ac.cn (L.X.); dzhang1987@icmm.ac.cn (D.Z.); \\ yhshi@icmm.ac.cn (Y.-H.S.); justuswu@163.com (M.-L.W.) \\ 2 School of Chinese Medicine, Faculty of Medicine, The Chinese University of Hong Kong, \\ Shatin 999077, N.T., Hong Kong, China; lisaxian@cuhk.edu.hk (Y.-F.X.); paulip@cuhk.edu.hk (S.-P.I.); \\ linzx@cuhk.edu.hk (Z.-X.L.) \\ 3 Amway (China) Botanical Research and Development Center, Wuxi 214145, China; tony.dong@Amway.com \\ * Correspondence: lwu@icmm.ac.cn (L.W.); wsun@icmm.ac.cn (W.S.); Tel.: +86-10-6409-6302 (L.W. \& W.S.) \\ + These authors contributed equally to this work.
}

Academic Editor: Mingfei Zhou

Received: 13 July 2018; Accepted: 23 August 2018; Published: 24 August 2018

\begin{abstract}
The genus Sanguisorba, which contains about 30 species around the world and seven species in China, is the source of the medicinal plant Sanguisorba officinalis, which is commonly used as a hemostatic agent as well as to treat burns and scalds. Here we report the complete chloroplast (cp) genome sequences of four Sanguisorba species (S. officinalis, S. filiformis, S. stipulata, and S. tenuifolia var. alba). These four Sanguisorba cp genomes exhibit typical quadripartite and circular structures, and are 154,282 to $155,479 \mathrm{bp}$ in length, consisting of large single-copy regions (LSC; 84,405-85,557 bp), small single-copy regions (SSC; 18,550-18,768 bp), and a pair of inverted repeats (IRs; 25,576-25,615 bp). The average GC content was $\sim 37.24 \%$. The four Sanguisorba cp genomes harbored 112 different genes arranged in the same order; these identical sections include 78 protein-coding genes, 30 tRNA genes, and four rRNA genes, if duplicated genes in IR regions are counted only once. A total of 39-53 long repeats and 79-91 simple sequence repeats (SSRs) were identified in the four Sanguisorba cp genomes, which provides opportunities for future studies of the population genetics of Sanguisorba medicinal plants. A phylogenetic analysis using the maximum parsimony (MP) method strongly supports a close relationship between S. officinalis and S. tenuifolia var. alba, followed by S. stipulata, and finally S. filiformis. The availability of these cp genomes provides valuable genetic information for future studies of Sanguisorba identification and provides insights into the evolution of the genus Sanguisorba.
\end{abstract}

Keywords: Sanguisorba; chloroplast genome; molecular structure; phylogenetic analysis

\section{Introduction}

The genus Sanguisorba belongs to the Rosaceae; there are about 30 species in the genus Sanguisorba in the world, mainly distributed in Asia, Europe, and North America (eFlora of China: http:/ /www.eflora.cn/). There are seven species and six varieties of Sanguisorba in China [1], distributed in both northern and southern China, especially in the northeast provinces. Sanguisorba officinalis has been recorded as a medicinal plant that is commonly used to treat water and fire burns, hemorrhoidal bleeding, and hematochezia [2]. Diyu Shengbai Tablet, a Chinese patent medicine, is mainly composed of S. officinalis, and contains active chemical components including saponins, flavonoids and tannins [3]. It can protect the 
hematopoietic system, elevate the peripheral blood white blood cells, neutrophils, and platelets, improve bone marrow micro-circulation, and adjust and improve body immunity and other functions. It is also often clinically used as an adjuvant during chemotherapy [3].

The chloroplast genome is $\sim 100-150 \mathrm{~kb}$ in length and contains a wealth of evolutionary information, which can be used to reveal phylogenetic relationships among closely related species and can also be valuable for species identification [4,5]. It has been widely used in species identification, phylogenetic evolution, and genetic engineering-related research [6,7]. With the rapid development of high-throughput sequencing technologies and bioinformatics tools, the cost of sequencing chloroplast genome has been significantly reduced, making the large-scale acquisition of chloroplast genomic sequences possible [8,9]. This has made possible the study of chloroplast genomes in terms of population genetic structure, phylogenetic evolution, and species identification.

However, molecular research on the genus Sanguisorba is still very scarce. Currently, there are no reports on the chloroplast genome sequence of the genus Sanguisorba, which seriously hampers molecular identification, phylogenetic, genetic, and breeding research involving the genus. In this study, we report the chloroplast genome assembly, annotation, and structural analysis of four Sanguisorba species (S. officinalis, S. filiformis, S. stipulata, and S. tenuifolia var. alba) as well as the complete chloroplast genome sequences of these species, which are the first four sequenced members of the genus Sanguisorba. In addition, we compared the chloroplast genomes of the four Sanguisorba species in detail (e.g., based on IR expansion/contraction and difference regions). From this we constructed a phylogenetic tree using the maximum parsimony (MP) method based on both the whole cp genome and on common protein-coding genes, respectively. Overall, our results provide useful genetic information on the chloroplast of Sanguisorba species, as well as their relative position in phylogenetic tree.

\section{Results and Discussion}

\subsection{Chloroplast Genome Assembly and Features}

Using an Illumina HiSeq X platform, four Sanguisorba species were sequenced to produce $11,554,422-18,828,898$ paired-end raw reads. After screening these paired-end reads, 598,166 to $1,080,144 \mathrm{cp}$ genome reads were successfully mapped with 569X to 1032X sequencing depth (Table 1). In this study, the sequencing depth was high enough to satisfy the technical requirements of an organelle genome assembly. In total, the complete cp genomes of the four Sanguisorba species were similar in length, ranging from 155,127 bp (S. stipulata) to 155,479 bp (S. officinalis) (Figure 1 and Figures S1-S3, and Table 1), with the typical quadripartite structure of angiosperms. All four cp genomes contained a large single-copy regions (LSC, 84,405-85,557 bp) and a small single-copy regions (SSC, 18,550-18,768bp), separated by a pair of inverted repeats regions (IRs, 25,576-25,615 bp).

Table 1. Sequence information and Illumina next-generation sequencing (NGS) data of the four Sanguisorba chloroplast genomes.

\begin{tabular}{|c|c|c|c|c|c|c|c|c|}
\hline Species & Raw Reads No. & $\begin{array}{c}\text { Mapped } \\
\text { Reads No. }\end{array}$ & $\begin{array}{l}\text { Sequencing } \\
\text { Depth }\end{array}$ & $\begin{array}{l}\text { Cp Genome } \\
\text { Length (bp) }\end{array}$ & $\begin{array}{c}\text { GC Content } \\
(\%)\end{array}$ & $\begin{array}{l}\text { LSC }^{a} \\
\text { (bp) }\end{array}$ & $\begin{array}{l}\text { SSC }^{a} \\
\text { (bp) }\end{array}$ & $\begin{array}{l}\text { IRs }^{a} \\
(\mathrm{bp})\end{array}$ \\
\hline S. officinalis & $11,554,422$ & 609,666 & $581 X$ & 155,479 & 37.19 & 85,547 & 18,768 & 25,582 \\
\hline S. filiformis & $16,876,554$ & 656,271 & $628 X$ & 154,282 & 37.33 & 84,405 & 18,659 & 25,609 \\
\hline S. tenuifolia var. alba & $18,366,336$ & 598,166 & $569 X$ & 155,457 & 37.20 & 85,557 & 18,748 & 25,576 \\
\hline
\end{tabular}

${ }^{\text {a }}$ LSC (large single-copy regions), SSC (small single-copy regions), and IRs (inverted repeats regions).

The average GC content of the four Sanguisorba cp genomes was $37.23 \%$; in this respect they showed only minor differences from one another and resembled the cp genomes of other reported Rosaceae species [10-12]. Nevertheless, the GC content is unevenly distributed in the four Sanguisorba cp genomes. The GC content of the IR regions $(\sim 42.7 \%)$ is significantly higher than in the LSC region $(\sim 35.3 \%)$ or the 
SSC regions $(\sim 31.3 \%)$. We speculate that this may be a reason for the divergence of the conservation between the IR and SC regions [8,13].

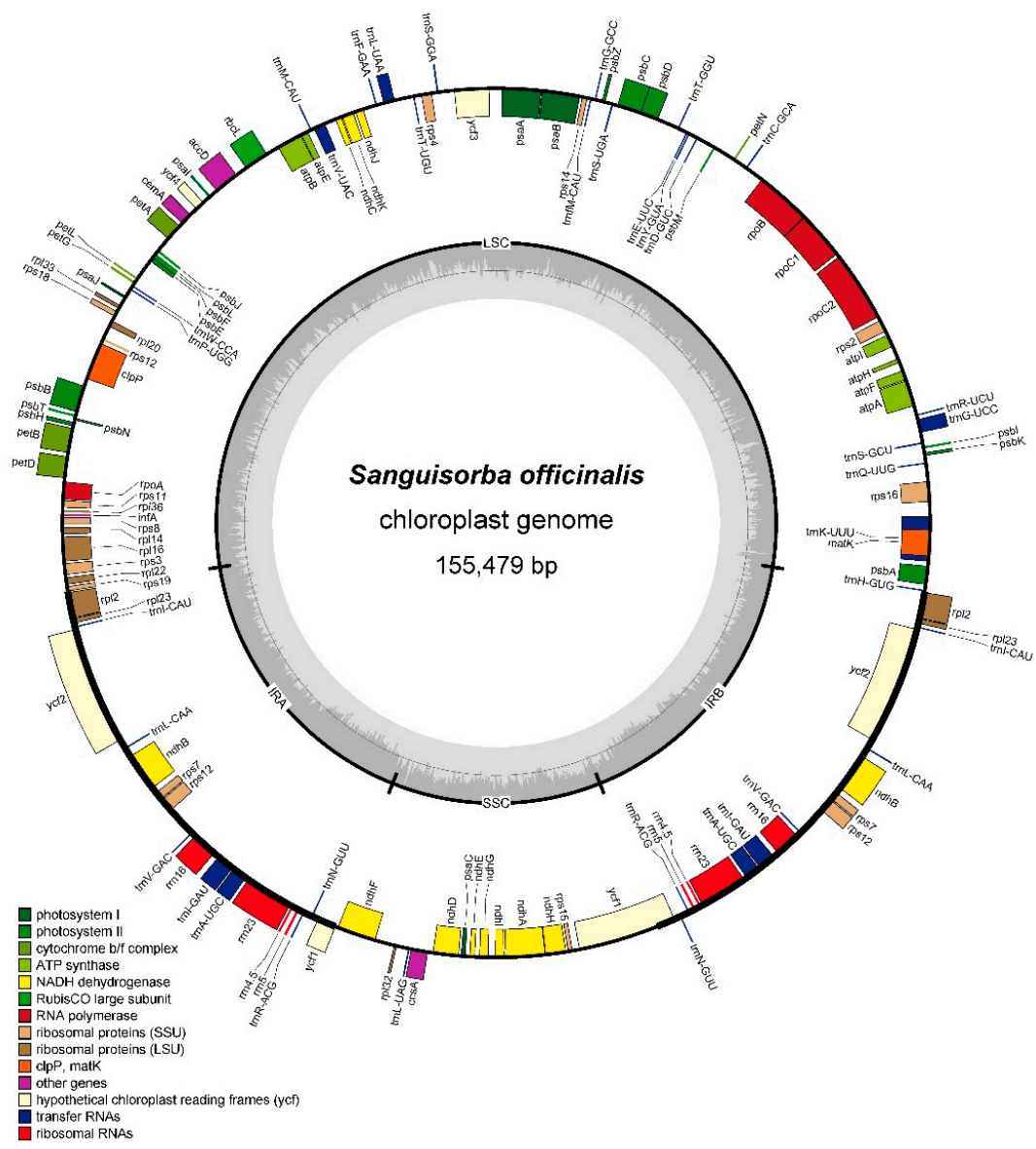

Figure 1. Gene map of Sanguisorba officinalis chloroplast genome. Genes shown inside the circle are transcribed clockwise, and those outside are counterclockwise. Genes in different functional groups are color-coded.

All four Sanguisorba cp genomes possessed 112 unique genes including 78 protein-coding genes, 30 tRNA genes, and four rRNA genes (Table 2). Of these, six protein-coding genes, seven tRNA genes, and four rRNA genes are duplicated in the IR regions, making a total of 129 genes shared (Table 2). Our results showed that the four Sanguisorba cp genomes were highly conserved in gene type, order, and content. We classified the 112 genes into different categories according to their function, and the details are shown in Table 2. In addition, two pseudogenes ( $y c f 1$ and infA) were found in the four $\mathrm{cp}$ genomes. There were 18 genes located in the IR regions as follows: $r r n 16, r r n 23, r r n 5, r r n 4.5, \operatorname{trn} A-U G C$, trnI-CAU, trnI-GAU, trnL-CAA, trnN-GUU, trnR-ACG, trnV-GAC, rps7, rps12, rpl2, rpl23, ndhB, ycf1, and $y c f 2$ (Figure 1 and Figures S1-S3). rps12 is a trans-spliced gene, in which two $3^{\prime}$ end residues are located in the IR region and the 5' end in the LSC region (Figure 1 and Figures S1-S3). This is a common phenomenon in the cp genomes of higher plants [14,15]. Significantly, the ycf15 gene is located in cp genome of most angiosperm while is absent from the Sanguisorba cp genomes. This phenomenon was also found to occur in Cedrela odorata [7], Schisandra chinensis [8], Cremastra appendiculata [16] and Aristolochia debilis [17]. 
Table 2. List of genes encoded by the four Sanguisorba chloroplast genomes.

\begin{tabular}{|c|c|c|}
\hline Category & Group & Name \\
\hline \multirow{6}{*}{ Self-replication } & rRNA genes & $r r n 4.5 a, r r n 5 a, r r n 16 a, r r n 23 a$ \\
\hline & tRNA genes & $\begin{array}{l}\operatorname{trn} A-U G C C^{*}, \mathrm{a}, \operatorname{trn} C-G C A, \operatorname{trn} D-G U C, \operatorname{trn} E-U U C, \operatorname{trn} F-G A A, \\
\operatorname{trnfM}-C A U, \operatorname{trn} G-G C C, \operatorname{trn} G-U C C^{*}, \operatorname{trn} H-G U G, \operatorname{trn} I-C A U^{\text {a }}\end{array}$ \\
\hline & & 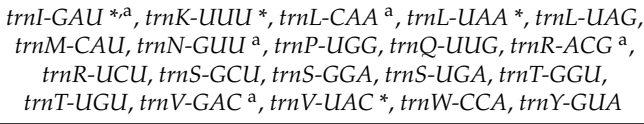 \\
\hline & Small subunit of ribosome & $\begin{array}{c}r p s 2, r p s 3, r p s 4, r p s 7^{\mathrm{a}}, r p s 8, r p s 11, r p s 12 * * \mathrm{a} \\
r p s p s 18, r p s 19\end{array}$ \\
\hline & Large subunit of ribosome & rpl2 ${ }^{*} \mathrm{a}$, rpl14, rpl16 ${ }^{*}, r p l 20, r p l 22, r p l 23^{\mathrm{a}}, \mathrm{rpl32}, \mathrm{rpl33}, \mathrm{rpl} 36$ \\
\hline & DNA dependent RNA polymerase & $r p o A, r p o B, r p o C 1 *, r p o C 2$ \\
\hline \multirow{6}{*}{ Genes for phytosynthesis } & $\begin{array}{l}\text { Subunits of } \\
\text { NADH-dehydrogenase }\end{array}$ & $\begin{array}{c}n d h A^{*}, n d h B^{*, a}, n d h C, n d h D, n d h E, n d h F, n d h G, n d h H n d h I, \\
n d h J, n d h K\end{array}$ \\
\hline & Subunits of photosystem I & $p s a A, p s a B, p s a C, p s a I, p s a J$ \\
\hline & Subunits of photosystem II & $\begin{array}{c}p s b A, p s b B, p s b C, p s b D, p s b E, p s b F, p s b H, p s b I, p s b J, p s b K, p s b L, \\
p s b M, p s b N, p s b T, p s b Z\end{array}$ \\
\hline & $\begin{array}{l}\text { Subunits of cytochrome b/f } \\
\text { complex }\end{array}$ & $\operatorname{pet} A, \operatorname{pet} B^{*}, \operatorname{pet} D^{*}, \operatorname{pet} G, \operatorname{pet} L, \operatorname{pet} N$ \\
\hline & Subunits of ATP synthase & $\operatorname{atp} A, \operatorname{atpB}, \operatorname{atpE}, \operatorname{atpF}, \operatorname{atpH}$, atpl \\
\hline & Large subunit of RuBisCO & $r b c L$ \\
\hline \multirow{5}{*}{ Other genes } & Maturase & matK \\
\hline & Envelope membrane protein & $\operatorname{cem} A$ \\
\hline & $\begin{array}{l}\text { Subunit of } \\
\text { Acetyl-CoA-carboxylase }\end{array}$ & $a c c D$ \\
\hline & C-type cytochrome synthesis gene & $\operatorname{ccs} A$ \\
\hline & Protease & $\operatorname{clp} P^{* *}$ \\
\hline \multirow{2}{*}{ Genes of unknown function } & Open Reading Frames (ORF, ycf) & $y c f 1, y c f 2 a, y c f 3 * *, y c f 4$ \\
\hline & Pseudo genes & $y c f 1, \inf A$ \\
\hline
\end{tabular}

${ }^{*}$ Gene with one intron, ${ }^{* *}$ Gene with two introns, ${ }^{\text {a }}$ Gene with two copies.

Introns play an important role in the regulation of alternative gene splicing $[18,19]$. We found that 17 genes contained introns in all four Sanguisorba cp genomes, of which 11 are protein-coding genes and six are tRNA genes. 14 of the 17 contain a single intron, whereas three ( $c l p P, r p s 12$, and $y c f 3)$ have two introns. The largest intron, located into the trnK-UUU gene, ranged $2508 \mathrm{bp}$ to $2516 \mathrm{bp}$ in the four species (Table 3 and Tables S1-S3). The matK gene is located in the intron of trnK-UUU gene.

Table 3. The length of exons and introns in genes with introns in the Sanguisorba officinalis chloroplast genome.

\begin{tabular}{|c|c|c|c|c|c|c|c|}
\hline No. & Gene & Location & Exon I (bp) & Intron I (bp) & Exon II (bp) & Intron I (bp) & Exon III (bp) \\
\hline 1 & clpP & LSC & 69 & 938 & 291 & 658 & 228 \\
\hline 2 & $n d h A$ & SSC & 563 & 1185 & 541 & & \\
\hline 3 & $n d h B$ & IR & 777 & 682 & 756 & & \\
\hline 4 & petB & LSC & 6 & 761 & 657 & & \\
\hline 5 & petD & LSC & 9 & 750 & 474 & & \\
\hline 6 & rpl16 & LSC & 8 & 1011 & 403 & & \\
\hline 7 & $r p l 2$ & IR & 391 & 673 & 434 & & \\
\hline 8 & rpoC1 & LSC & 435 & 749 & 1620 & & \\
\hline 9 & rps $12 *$ & LSC & 114 & - & 232 & 543 & 26 \\
\hline 10 & rps16 & LSC & 39 & 899 & 228 & & \\
\hline 11 & $\operatorname{trn} A-U G C$ & IR & 38 & 814 & 35 & & \\
\hline 12 & $\operatorname{trnG-UCC}$ & LSC & 23 & 698 & 48 & & \\
\hline 13 & $\operatorname{trnI-GAU}$ & $\mathrm{IR}$ & 42 & 949 & 35 & & \\
\hline 14 & trnK-UUU & LSC & 37 & 2516 & 35 & & \\
\hline 15 & trnL-UAA & LSC & 37 & 554 & 50 & & \\
\hline 16 & $\operatorname{trn} V-U A C$ & LSC & 39 & 601 & 37 & & \\
\hline 17 & $y c f 3$ & LSC & 126 & 723 & 228 & 766 & 153 \\
\hline
\end{tabular}

* rps12 is a trans-spliced gene, of which two $3^{\prime}$ end residues are located in the IR region and the $5^{\prime}$ end in the LSC region. 


\subsection{Codon Usage}

The total length of the protein coding genes from the four Sanguisorba cp genomes is $78,582 \sim 78,612 \mathrm{bp}$, and these genes are encoded by $22,760 \sim 22,768$ codons. Protein coding genes thus accounted for $50.6 \sim 50.9 \%$ of the whole genome sequence. The most frequent amino acid is leucine, with $2387 \sim 2400(10.5 \%)$ of the codons, but cysteine is the least frequent in the four Sanguisorba cp genomes, with only 260 262 (1.1\%) of all codons. Within the protein-coding sequences (CDS), the AT content of codons at the first to third positions is $54.5 \%, 61.9 \sim 62.0 \%$, and $69.5 \sim 69.6 \%$, respectively. The fact is that the AT content of the codons is the highest with the third position, and it's common in land plants $[7,13,20,21]$. The same phenomenon was also found in the frequency of codon usage. All preferred synonymous codons (RSCU $>1$ ) ended with A or U except the codons of $\operatorname{trnL}$-CAA; however, most non-preferred synonymous codons (RSCU $<1$ ) ended with $\mathrm{G}$ or C (Table 4 and Table S4-S6).

Table 4. Codon usage in the Sanguisorba officinalis chloroplast genomes. RSCU: Relative Synonymous Codon Usage.

\begin{tabular}{|c|c|c|c|c|c|c|c|c|c|}
\hline Amino Acid & Codon & Count & RSCU & tRNA & Amino Acid & Codon & Count & RSCU & tRNA \\
\hline Phe & UUU & 899 & 1.38 & & Tyr & UAU & 682 & 1.61 & \\
\hline Phe & UUC & 401 & 0.62 & $\operatorname{trnF-GAA}$ & Tyr & UAC & 165 & 0.39 & $\operatorname{trn} Y-G U A$ \\
\hline Leu & UUA & 810 & 2.03 & $\operatorname{trnL}-U A A$ & Stop & UAA & 43 & 1.65 & \\
\hline Leu & UUG & 466 & 1.17 & $\operatorname{trnL}-C A A$ & Stop & UAG & 20 & 0.77 & \\
\hline Leu & CUU & 503 & 1.26 & & $\mathrm{His}$ & CAU & 403 & 1.51 & \\
\hline Leu & CUC & 148 & 0.37 & & His & CAC & 132 & 0.49 & $\operatorname{trnH}-G U G$ \\
\hline Leu & CUA & 306 & 0.77 & $\operatorname{trnL-UAG}$ & Gln & CAA & 616 & 1.53 & trnQ-UUG \\
\hline Leu & CUG & 156 & 0.39 & & Gln & CAG & 191 & 0.47 & \\
\hline Ile & AUU & 983 & 1.5 & & Asn & AAU & 825 & 1.53 & \\
\hline Ile & AUC & 369 & 0.56 & trnI-GAU & Asn & AAC & 256 & 0.47 & $\operatorname{trnN-GUU}$ \\
\hline Ile & AUA & 614 & 0.94 & & Lys & AAA & 925 & 1.54 & trnK-UUU \\
\hline Met & AUG & 531 & 1 & $\begin{array}{c}\text { trnfM-CAU, trnI-CAU, } \\
\text { trnM-CAU }\end{array}$ & Lys & AAG & 280 & 0.46 & \\
\hline Val & GUU & 471 & 1.48 & & Asp & GAU & 712 & 1.62 & \\
\hline Val & GUC & 152 & 0.48 & $\operatorname{trn} V-G A C$ & Asp & GAC & 168 & 0.38 & $\operatorname{trnD-GUC}$ \\
\hline Val & GUA & 474 & 1.48 & $\operatorname{trn} V-U A C$ & Glu & GAA & 904 & 1.52 & trnE-UUC \\
\hline Val & GUG & 180 & 0.56 & & Glu & GAG & 287 & 0.48 & \\
\hline Ser & UCU & 469 & 1.69 & & Cys & UGU & 204 & 1.56 & \\
\hline Ser & UCC & 263 & 0.95 & $\operatorname{trnS}-G G A$ & Cys & UGC & 57 & 0.44 & $\operatorname{trn} C-G C A$ \\
\hline Ser & UCA & 306 & 1.1 & trnS-UGA & Stop & UGA & 15 & 0.58 & \\
\hline Ser & UCG & 171 & 0.61 & & Trp & UGG & 396 & 1 & $\operatorname{trnW}-\mathrm{CC} A$ \\
\hline Pro & CCU & 352 & 1.47 & & Arg & CGU & 307 & 1.36 & $\operatorname{trnR}-A C G$ \\
\hline Pro & CCC & 198 & 0.83 & & Arg & CGC & 95 & 0.42 & \\
\hline Pro & CCA & 257 & 1.08 & trnP-UGG & Arg & CGA & 312 & 1.38 & \\
\hline Pro & CCG & 149 & 0.62 & & Arg & CGG & 103 & 0.46 & \\
\hline Thr & $\mathrm{ACU}$ & 465 & 1.59 & & Ser & AGU & 349 & 1.25 & \\
\hline Thr & $\mathrm{ACC}$ & 224 & 0.76 & $\operatorname{trnT-GGU}$ & Ser & AGC & 111 & 0.4 & trnS-GCU \\
\hline Thr & $\mathrm{ACA}$ & 348 & 1.19 & $\operatorname{trnT-UGU}$ & Arg & AGA & 391 & 1.74 & trnR-UCU \\
\hline Thr & $\mathrm{ACG}$ & 135 & 0.46 & & Arg & AGG & 144 & 0.64 & \\
\hline Ala & GCU & 576 & 1.79 & & Gly & GGU & 524 & 1.32 & \\
\hline Ala & GCC & 201 & 0.63 & & Gly & GGC & 192 & 0.48 & $\operatorname{trn} G-G C C$ \\
\hline Ala & GCA & 348 & 1.08 & $\operatorname{trn} A-U G C$ & Gly & GGA & 568 & 1.43 & trnG-UCC \\
\hline Ala & GCG & 161 & 0.5 & & Gly & GGG & 305 & 0.77 & \\
\hline
\end{tabular}

\subsection{Long Repeats and SSR Analysis}

For long repeats analysis, the four cp genomes enclose long repeats with a total number ranging from 39 to 53 with at least 30 bp per repeat unit. Taking S. officinalis as an example, a number of 49 repeats were detected. These included 24 palindromic repeats, 17 forward repeats, six reverse repeats, and two complement repeats. Most repeats showed lengths between 30 and $44 \mathrm{bp}$ and are in intergenic regions or intron sequences.

SSRs, also called as microsatellites, are tandemly repeated sequences that consist of 1-6 nucleotide repeat units. SSRs are widely distributed in cp genomes in general and are important for studies of plant populations. Because of their high level of polymorphism, SSRs are widely used as molecular markers for species authentication, molecular breeding, and population genetics [22-25]. Here, we identified many SSRs in the cp genomes, ranging from 79 in S. tenuifolia var. alba to 91 
in S. stipulata. Most of the SSRs are mononucleotide repeats, whose amount ranges from 55 (S. tenuifolia var. alba) to 69 (S. stipulata). The number of di-, tri-, tetra-, penta-, and hexanucleotide repeats found was 9 12, 3 4, 7 9, 0 1, and 1 2, respectively (Table 5). Most of the mononucleotide SSRs belonged to the A/T type in the four Sanguisorba species. The highest number of SSRs found was in S. stipulata, which showed 68 of 69 identified mononucleotide SSRs. The lowest number of SSRs found was 55 of the 59 found in S. officinalis. These results are consistent with those of previous studies that found that polyadenine (polyA) and polythymine (polyT) content were higher than polyguanine (polyG) and polycytosine (polyC) content in the cpSSRs of many plants [26]. We speculate that the abundance of A/T SSRs may be associated with the AT richness of these cp genomes $[13,27]$.

Table 5. Types and numbers of SSRs found in the four Sanguisorba chloroplast genomes.

\begin{tabular}{cccccc}
\hline \multirow{2}{*}{ SSR Type } & \multirow{2}{*}{ Repeat Unit } & \multicolumn{3}{c}{ Number } \\
\cline { 3 - 6 } & & S. officinalis & S. filiformis & S. stipulata & S. tenuifolia var. alba \\
\hline \multirow{2}{*}{ Mono } & A/T & 55 & 56 & 68 & 53 \\
& C/G & 4 & 3 & 1 & 2 \\
Di & AT/AT & 11 & 9 & 8 & 11 \\
& AG/CT & 1 & 1 & 1 & 1 \\
Tri & AAT/ATT & 3 & 4 & 3 & 4 \\
& AAAT/ATTT & 4 & 3 & 5 & 1 \\
& AAAG/CTTT & 1 & 1 & 1 & 1 \\
& ACAT/ATGT & 1 & 1 & 1 & 1 \\
& AGAT/ATCT & 1 & 1 & 1 & 0 \\
Penta & AATT/AATT & 0 & 1 & 1 & 0 \\
Hexa & AAATT/AATTT & 1 & 0 & 0 & 0 \\
& AAAGGG/CCCTTT & 0 & 2 & 0 & 79 \\
\hline
\end{tabular}

\subsection{IR Contraction and Expansion}

It is well known that IRs are the most conserved regions in chloroplast genomes, and the contraction and expansion at the borders of IR regions are common evolutionary events. It is also a main cause of length variation in the chloroplast genomes [28,29]. In this study, we compared the IR/SSC and IR/LSC boundaries of the four Sanguisorba cp genomes (Figure 2). In the four Sanguisorba species, the IRb/SSC boundary extends into functional ycf1 genes, yielding a pseudogene $y c f 1$, which have a length of 1106 1201 bp in the four species. A previous study reported that the pseudogene ycf1 may be useful for researching variation among cp genomes in higher plants or algae [30]. In addition, we found no overlap between the ycf1 pseudogene and $n d h F$ in the four species. The $n d h F$ gene is found in the SSC region, and was $138 \mathrm{bp}, 90 \mathrm{bp}$, four bp, and $117 \mathrm{bp}$ away from the IRb/SSC boundary in S. officinalis, S. filiformis, S. stipulata, and S. tenuifolia var. alba, respectively. The trnH gene was found in the same position of the same LSC region in the four species, which is only two bp away from the $\mathrm{IRb} / \mathrm{SSC}$ boundary. In the cp genome, variation in the IR/SSC and IR/LSC boundaries is governed by a dynamic and random process that is confined to conservative expansions and contractions [31,32]. There are many studies about the mechanisms responsible for IR expansion, and the leading view is that short IR expansions could be caused by gene conversion, but large IR expansions may be the result of double-strand DNA break repair (DSBR) [33,34]. In contrast, there are few reports on the mechanisms of IR contraction. However, Peery et al. proposed that DSBR theory was not only the main mechanism of IR region expansion, but also the main mechanism of IR region contraction [35]. 


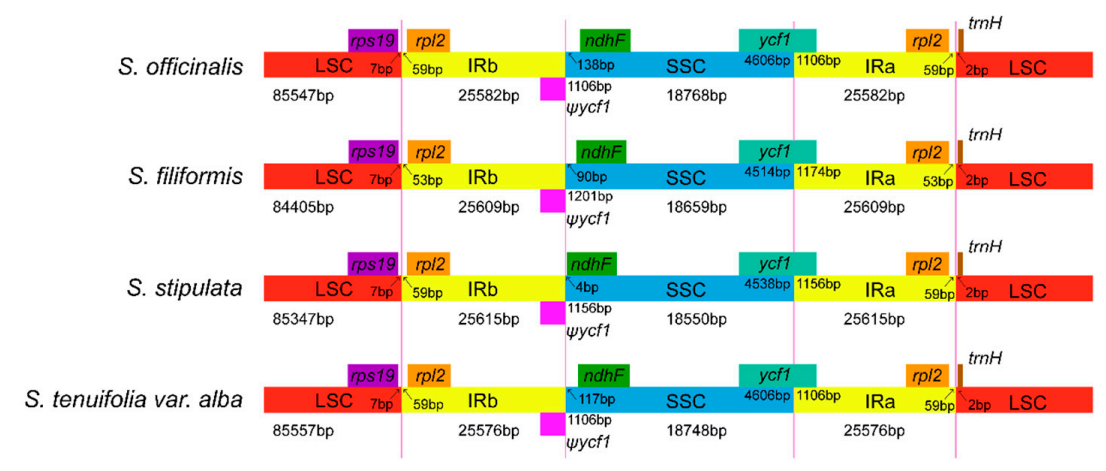

Figure 2. Comparison of the border regions of the LSC, SSC, and IR among four chloroplast genomes. $\Psi$ : pseudogenes.

\subsection{Comparative Chloroplast Genomic Analysis}

With the annotated S. officinalis cp genome as a reference, the whole cp genome of the four Sanguisorba species were compared and drawn by mVISTA to show sequence divergence (Figure 3), which is important for further phylogenetic analyses and species identification. Comparative genome analysis found that there is a high similarity between the cp genomes of all Sanguisorba species. The LSC and SSC regions are more divergent than the two IR regions, which is common in other higher plants and may be due to copy corrections between two IR regions by gene conversion [36]. Moreover, the coding regions have less variability proportions than the non-coding regions. The highest divergence among the four Sanguisorba cp genomes occurs in the intergenic spacers region, which, contains trnE-trnT, trnS-psbZ, trnS-ycf3, trnF-ndhJ, accD-psal, and ycf1-ndhF. In this study, we found that the more conserved coding regions are the four rRNA located in IR region.

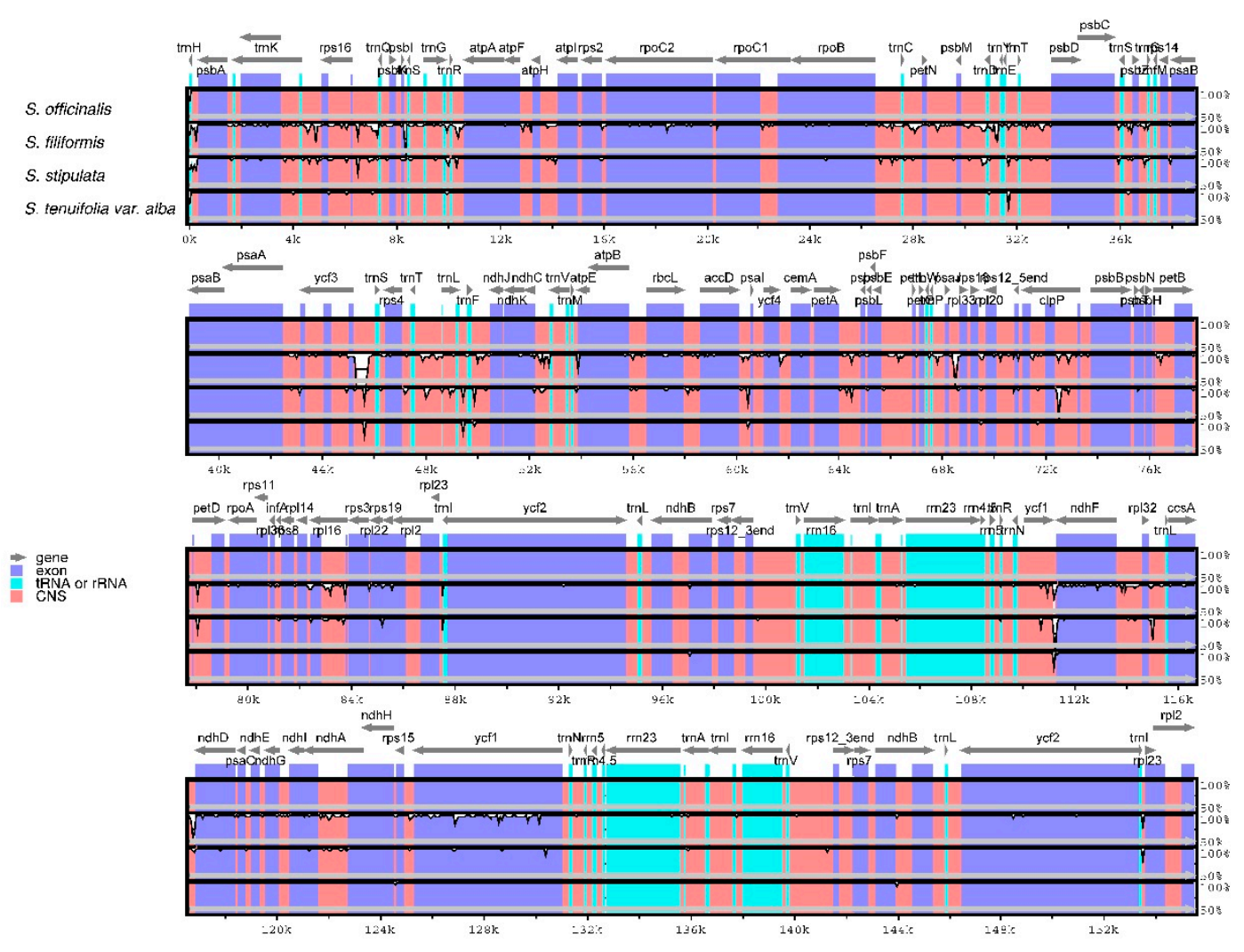

Figure 3. Comparison of the four Sanguisorba chloroplast genomes using mVISTA. CNS indicates conserved noncoding sequences. The Y-scale represents the percent identity between $50 \%$ and $100 \%$. 


\subsection{Phylogenetic Analysis}

Chloroplast genomes contain abundant genetic information that is widely applied in plant identification and phylogenetic studies [6,37-39]. Sanguisorba belongs to the subfamily Rosoideae in the Rosaceae. Previous studies have reported phylogenetic relationships within the Rosaceae that were analyzed based on chloroplast regions [40,41]. Here, the availability of the completed cp genomes and protein coding genes of the four Sanguisorba species provide us with sequence and gene information for studying the molecular evolution and phylogeny of the genus Sanguisorba [9,42]. In this study, two datasets (i.e., the whole complete $\mathrm{cp}$ genome and the set of protein coding genes) from the $\mathrm{cp}$ genomes of the four Sanguisorba species and one outgroup (Fragaria chiloensis) were used to perform phylogenetic analysis. Phylogenetic trees were generated using the maximum parsimony (MP) method based on two datasets with the same topologies (Figure 4 and Figure S4). For the four Sanguisorba species, S. officinalis has the closest relationship with S. tenuifolia var. alba, followed by S. stipulata, and has the least close relationship with the S. filiformis. In addition, both S. stipulata and S. filiformis group into a monophyletic clade.

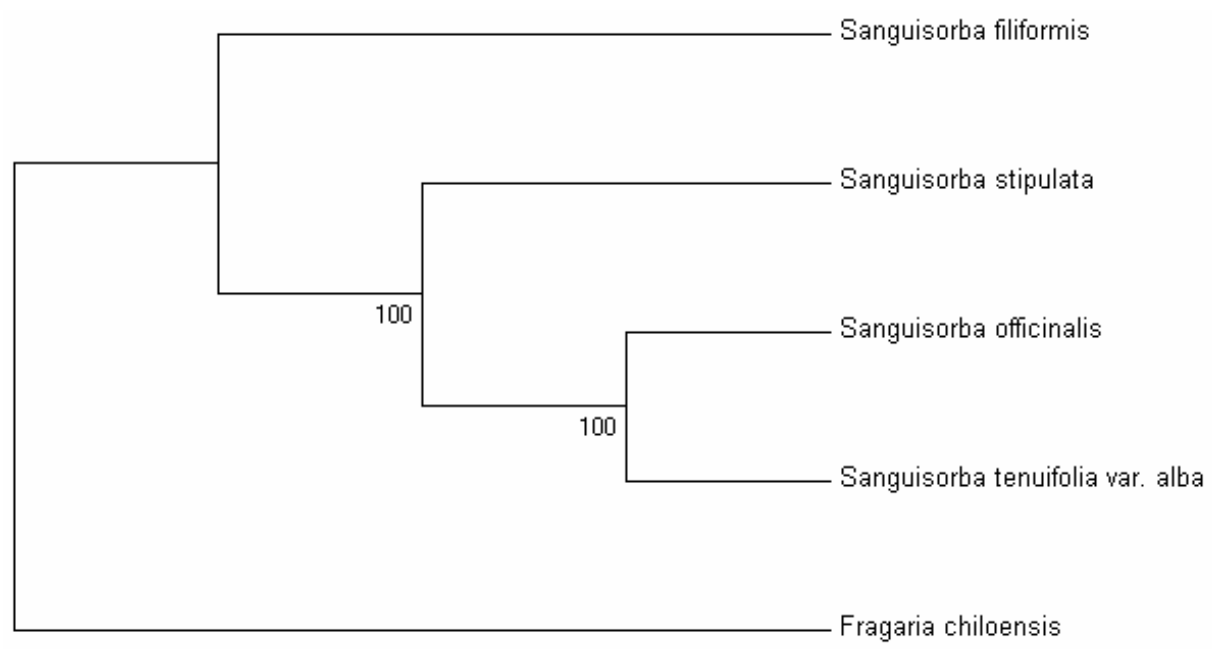

Figure 4. Phylogenetic relationships between the four Sanguisorba species determined by whole cp genome sequences using the maximum parsimony (MP) method. Fragaria chiloensis was set as the outgroup.

\section{Materials and Methods}

\subsection{Plant Materials and DNA Extraction}

Fresh leaves of four Sanguisorba species were collected from Jilin and Yunan Provinces in China. Then we washed the leaves powder with HF buffer $\left(100 \mathrm{mmol} \cdot \mathrm{L}^{-1}\right.$ Tris- $\mathrm{HCl} \mathrm{pH}$ 8.0, $20 \mathrm{mmol} \cdot \mathrm{L}^{-1}$ EDTA, $0.7 \mathrm{~mol} \cdot \mathrm{L}^{-1} \mathrm{NaCl}, 2 \% \mathrm{PVP}$, and $0.2 \%$ 2-mercaptoethanol). HF buffer $(600 \mu \mathrm{L})$ was added to leaves powder $(\sim 100 \mathrm{mg})$, the mixture vortexed vigorously for $3 \mathrm{~min}$, centrifuged for $5 \mathrm{~min}$ at $12,000 \mathrm{rpm}$, and the supernatant discarded. Finally the total genomic DNA of each sample was isolated from the leaves powder by Plant Genomic DNA Kits (Tiangen Biotech Co., Beijing, China), according to the manufacturer's instructions. The DNA quality and quantity of each sample was estimated by a NanoDrop 2000 Spectrophotometer (Nanodrop Technologies, Wilmington, DE, USA) and a Qubit3.0 Fluorometer (Thermo Scientific, Waltham, MA, USA), as well as by agarose gel electrophoresis.

\subsection{Chloroplast Genome Sequencing, Assembly and Annotation}

After DNA was purified and prepared, $\sim 2 \mu \mathrm{g}$ was used to construct shotgun libraries. Genomic DNA was taken and sheared into 450 bp contigs with the Covaris M220 Focused-ultrasonicator (Covaris, Woburn, MA, USA). The library was constructed by TruSeq ${ }^{\mathrm{TM}}$ DNA 
Sample Prep Kit (Illumina Inc., San Diego, CA, USA), according to the manufacturer's instructions. An Illumina HiSeq $X$ platform was used for sequencing. Clean reads were obtained by using the Fastqc trim tool [43]. We then extracted cp-like reads from trimmed reads by performing BLASTs [44] using reference sequences (Rosa roxburghii, accession No.: NC_032038). Sequence assembly was performed by using SOAPdenovo [45], and the contigs were aligned using SSPACE [46]. The complete chloroplast genomes of the four Sanguisorba species were annotated using the CpGAVAS web service [47]. The tRNA genes were confirmed using tRNAscan-SE [48,49]. OGDRAW software (http:/ / ogdraw.mpimp-golm.mpg.de/) [50] was used to draw circular cp genome maps for each species. The validated complete cp genome of the four Sanguisorba species were deposited in GenBank (https:/ / www.ncbi.nlm.nih.gov/): S. officinalis, MF678801; S. filiformis, MF678800; S. stipulata, MF678798; and S. tenuifolia var. alba, MF678799.

\subsection{Genome Comparison and Structural Analyses}

The IR and SC boundary regions of the four Sanguisorba species were compared and examined. Comparison of the four cp genomes was performed using the Shuffle-LAGAN mode in mVISTA [51,52], with the annotation of $S$. officinalis used as the reference. In addition, we analyzed the codon usage, relative synonymous codon usage values (RSCU), and GC content using MEGA5 [53]. SSRs were identified by MISA (http:/ /pgrc.ipk-gatersleben.de/misa/) [54] with minimum repeat numbers of 10, 5, 4, 3, 3, and 3 for mono-, di-, tri-, tetra-, penta-, and hexanucleotides, respectively. The forward and inverted repeats in the Sanguisorba cp genome were detected using REPuter [55] with a minimal repeat sequence of $30 \mathrm{bp}$ and a sequence identity of $90 \%$.

\subsection{Phylogenetic Analyses}

Phylogenetic analyses were performed for the four Sanguisorba species using Fragaria chiloensis (Rosaceae) as an outgroup. The complete $\mathrm{cp}$ genome sequences and protein coding genes shared in four Sanguisorba species and Fragaria chiloensis (accession No.: NC_019601) [56] were aligned by ClustalW2 [57]. Phylogenetic trees were constructed using the maximum parsimony (MP) method in PAUP*4.0b10 [58]. A heuristic search was performed using the MULPARS option, with the random stepwise addition of sequences in 1000 replications and tree bisection reconnection (TBR) branch swapping. The branch support of the phylogenetic tree was 1000 bootstrap replicates.

\section{Conclusions}

The complete cp genome sequences of four Sanguisorba species (S. officinalis, S. filiformis, S. stipulata, and S. tenuifolia var. alba), the first four sequenced members of the genus Sanguisorba, were assembled, annotated and analyzed in this study. The genome structure, gene content, and gene order were similar in the four species. Long repeats and SSRs reported here provide opportunities for the development of new molecular markers to study medicinal plants in the genus Sanguisorba. Phylogenetic analysis strongly supported that $S$. officinalis has the closest relationship with $S$. tenuifolia var. alba, followed by S. stipulata, and then S. filiformis. The available genome data presented in this paper provides a basis for further research on the evolution of the genus Sanguisorba, as well as for species identification.

Supplementary Materials: Supplementary materials are available online. Table S1. The length of exons and introns in genes with introns in the Sanguisorba filiformis chloroplast genome. Table S2. The length of exons and introns in genes with introns in the Sanguisorba stipulata chloroplast genome. Table S3. The length of exons and introns in genes with introns in the Sanguisorba tenuifolia var. alba chloroplast genome. Table S4. Codon usage in the Sanguisorba filiformis chloroplast genome. Table S5. Codon usage in the Sanguisorba stipulata chloroplast genomes. Table S6. Codon usage in the Sanguisorba tenuifolia var. alba chloroplast genomes. Figure S1. Gene map of Sanguisorba filiformis chloroplast genome. Genes shown inside the circle are transcribed clockwise, and those outside are counterclockwise. Genes in different functional groups are color-coded. Figure S2. Gene map of Sanguisorba stipulata chloroplast genome. Genes shown inside the circle are transcribed clockwise, and those outside are counterclockwise. Genes in different functional groups are color-coded. Figure S3. Gene map of Sanguisorba tenuifolia var. alba chloroplast genom. Genes shown inside the circle are transcribed clockwise, and those outside are counterclockwise. Genes in different functional groups are color-coded. Figure S4. 
Phylogenetic relationships of the four Sanguisorba species constructed by protein coding genes using the maximum parsimony (MP) method. Fragaria chiloensis was set as the outgroup.

Author Contributions: X.-X.M. and Y.-F.X. performed the experiments; X.-X.M. and M.-L.W. assembled sequences and analyzed the data; L.W. wrote the manuscript; W.S. and L.W. conceived the research framework. L.X., D.Z., Y.-H.S., G.-Q.D., S.-P.I. and Z.-X.L. made revisions to the final manuscript. All authors have read and approved the final manuscript.

Funding: This research was funded by the Major Scientific and Technological Special Project for "Major New Drug Creation" (No. 2014ZX09201021-008 and 2017ZX09101002-003-001), and the National Natural Science Foundation of China (No. 81503192).

Conflicts of Interest: The authors declare no conflict of interest.

\section{References}

1. Yang, B.; Hu, J.; Zhang, F.; Li, J.; Liu, Q.; Pu, G.; Liu, H.; Zhang, Y. Herbal Textural Study on Sanguisorba officinalis L. Shandong Univ. TCM 2016, 5, 412-414.

2. State Pharmacopoeia Committee. Pharmacopoeia of the People's Republic of China; Medical Science and Technology Press: Beijing, China, 2015; Volume 1, p. 126.

3. Jia, L.; Xi, W.; Jin, G. Effect of Diyu Shengbai Tablets on Bone Marrow Depression Induced by Cyclophosphamide in Mice. Chin. J. Exp. Tradit. Med. Formul. 2012, 18, 251-254.

4. Freitas, A.; da Anunciação, R.; D'Oliveira-Matielo, C.; Stefenon, V. Chloroplast DNA: A Promising Source of Information for Plant Phylogeny and Traceability. J. Mol. Biol. Methods 2018, 1, 2.

5. Hong, S.-Y.; Cheon, K.-S.; Yoo, K.-O.; Lee, H.-O.; Cho, K.-S.; Suh, J.-T.; Kim, S.-J.; Nam, J.-H.; Sohn, H.-B.; Kim, Y.-H. Complete chloroplast genome sequences and comparative analysis of Chenopodium quinoa and C. album. Front. Plant Sci. 2017, 8, 1696. [CrossRef]

6. Leister, D.; Pesaresi, P. The genomic era of chloroplast research. Annu. Plant Rev. 2018, 1-29. [CrossRef]

7. Mader, M.; Pakull, B.; Blanc-Jolivet, C.; Paulini-Drewes, M.; Bouda, Z.H.-N.; Degen, B.; Small, I.; Kersten, B. Complete Chloroplast Genome Sequences of Four Meliaceae Species and Comparative Analyses. Int. J. Mol. Sci. 2018, 19, 701. [CrossRef]

8. Guo, H.; Liu, J.; Luo, L.; Wei, X.; Zhang, J.; Qi, Y.; Zhang, B.; Liu, H.; Xiao, P. Complete chloroplast genome sequences of Schisandra chinensis: Genome structure, comparative analysis, and phylogenetic relationship of basal angiosperms. Sci. China Life Sci. 2017, 60, 1286-1290. [CrossRef] [PubMed]

9. Zhang, Y.; Du, L.; Liu, A.; Chen, J.; Wu, L.; Hu, W.; Zhang, W.; Kim, K.; Lee, S.-C.; Yang, T.-J. The complete chloroplast genome sequences of five Epimedium species: Lights into phylogenetic and taxonomic analyses. Front. Plant Sci. 2016, 7, 306. [CrossRef]

10. Cheng, H.; Li, J.; Zhang, H.; Cai, B.; Gao, Z.; Qiao, Y.; Mi, L. The complete chloroplast genome sequence of strawberry (Fragaria $\times$ ananassa Duch.) and comparison with related species of Rosaceae. Peer 2017, 5, e3919. [CrossRef] [PubMed]

11. Kim, H.-W.; Kim, K.-J. The complete plastome sequence of Pentactina rupicola Nakai (Rosaceae), a genus endemic to Korea. Mitochondrial DNA Part B 2016, 1, 698-700. [CrossRef]

12. Bao, L.; Li, K.; Teng, Y.; Zhang, D. Characterization of the complete chloroplast genome of the wild Himalayan pear Pyrus pashia (Rosales: Rosaceae: Maloideae). Conserv. Genet. Resour. 2017, 9, 569-571. [CrossRef]

13. Yang, Y.; Yuanye, D.; Qing, L.; Jinjian, L.; Xiwen, L.; Yitao, W. Complete chloroplast genome sequence of poisonous and medicinal plant datura stramonium: Organizations and implications for genetic engineering. PLoS ONE 2014, 9, e110656. [CrossRef] [PubMed]

14. Howe, C.J.; Barbrook, A.C.; Koumandou, V.L.; Nisbet, R.E.R.; Symington, H.A.; Wightman, T.F. Evolution of the chloroplast genome. Philos. Trans. R. Soc. B Biol. Sci. 2003, 358, 99-107. [CrossRef] [PubMed]

15. Wang, M.; Cui, L.; Feng, K.; Deng, P.; Du, X.; Wan, F.; Weining, S.; Nie, X. Comparative analysis of Asteraceae chloroplast genomes: Structural organization, RNA editing and evolution. Plant Mol. Biol. Rep. 2015, 33, 1526-1538. [CrossRef]

16. Dong, W.-L.; Wang, R.-N.; Zhang, N.-Y.; Fan, W.-B.; Fang, M.-F.; Li, Z.-H. Molecular Evolution of Chloroplast Genomes of Orchid Species: Insights into Phylogenetic Relationship and Adaptive Evolution. Int. J. Mol. Sci. 2018, 19, 716. [CrossRef] [PubMed] 
17. Zhou, J.; Chen, X.; Cui, Y.; Sun, W.; Li, Y.; Wang, Y.; Song, J.; Yao, H. Molecular Structure and Phylogenetic Analyses of Complete Chloroplast Genomes of Two Aristolochia Medicinal Species. Int. J. Mol. Sci. 2017, 18, 1839. [CrossRef] [PubMed]

18. Smith, N.A.; Singh, S.P.; Wang, M.-B.; Stoutjesdijk, P.A.; Green, A.G.; Waterhouse, P.M. Gene expression: Total silencing by intron-spliced hairpin RNAs. Nature 2000, 407, 319-320. [CrossRef] [PubMed]

19. Graveley, B.R. Alternative splicing: Increasing diversity in the proteomic world. Trends Genet. 2001, 17, 100-107. [CrossRef]

20. Clegg, M.T.; Gaut, B.S.; Learn, G.H.; Morton, B.R. Rates and patterns of chloroplast DNA evolution. Proc. Natl. Acad. Sci. USA 1994, 91, 6795-6801. [CrossRef] [PubMed]

21. Yi, D.-K.; Kim, K.-J. Complete chloroplast genome sequences of important oilseed crop Sesamum indicum L. PLoS ONE 2012, 7, e35872. [CrossRef] [PubMed]

22. Dashnow, H.; Tan, S.; Das, D.; Easteal, S.; Oshlack, A. Genotyping microsatellites in next-generation sequencing data. BMC Bioinform. 2015, 16, A5. [CrossRef]

23. Chmielewski, M.; Meyza, K.; Chybicki, I.J.; Dzialuk, A.; Litkowiec, M.; Burczyk, J. Chloroplast microsatellites as a tool for phylogeographic studies: The case of white oaks in Poland. iForest 2015, 8, 765. [CrossRef]

24. Jiao, Y.; Jia, H.-M.; Li, X.-W.; Chai, M.-L.; Jia, H.-J.; Chen, Z.; Wang, G.-Y.; Chai, C.-Y.; van de Weg, E.; Gao, Z.-S. Development of simple sequence repeat (SSR) markers from a genome survey of Chinese bayberry (Myrica rubra). BMC Genom. 2012, 13, 201. [CrossRef] [PubMed]

25. Xue, J.; Wang, S.; Zhou, S.L. Polymorphic chloroplast microsatellite loci in Nelumbo (Nelumbonaceae). Am. J. Bot. 2012, 99, 240-244. [CrossRef] [PubMed]

26. Kuang, D.-Y.; Wu, H.; Wang, Y.-L.; Gao, L.-M.; Zhang, S.-Z.; Lu, L. Complete chloroplast genome sequence of Magnolia kwangsiensis (Magnoliaceae): Implication for DNA barcoding and population genetics. Genome 2011, 54, 663-673. [CrossRef] [PubMed]

27. Raveendar, S.; Na, Y.-W.; Lee, J.-R.; Shim, D.; Ma, K.-H.; Lee, S.-Y.; Chung, J.-W. The complete chloroplast genome of Capsicum annuum var. glabriusculum using Illumina sequencing. Molecules 2015, 20, 13080-13088. [PubMed]

28. Kim, K.-J.; Lee, H.-L. Complete chloroplast genome sequences from Korean ginseng (Panax schinseng Nees) and comparative analysis of sequence evolution among 17 vascular plants. DNA Res. 2004, 11, $247-261$. [CrossRef] [PubMed]

29. Raubeson, L.A.; Peery, R.; Chumley, T.W.; Dziubek, C.; Fourcade, H.M.; Boore, J.L.; Jansen, R.K. Comparative chloroplast genomics: Analyses including new sequences from the angiosperms Nuphar advena and Ranunculus macranthus. BMC Genom. 2007, 8, 174. [CrossRef] [PubMed]

30. De Cambiaire, J.-C.; Otis, C.; Lemieux, C.; Turmel, M. The complete chloroplast genome sequence of the chlorophycean green alga Scenedesmus obliquus reveals a compact gene organization and a biased distribution of genes on the two DNA strands. BMC Evol. Biol. 2006, 6, 37. [CrossRef] [PubMed]

31. Ma, J.; Yang, B.; Zhu, W.; Sun, L.; Tian, J.; Wang, X. The complete chloroplast genome sequence of Mahonia bealei (Berberidaceae) reveals a significant expansion of the inverted repeat and phylogenetic relationship with other angiosperms. Gene 2013, 528, 120-131. [CrossRef] [PubMed]

32. Shen, X.; Wu, M.; Liao, B.; Liu, Z.; Bai, R.; Xiao, S.; Li, X.; Zhang, B.; Xu, J.; Chen, S. Complete Chloroplast Genome Sequence and Phylogenetic Analysis of the Medicinal Plant Artemisia annua. Molecules 2017, 22, 1330. [CrossRef] [PubMed]

33. Goulding, S.E.; Wolfe, K.; Olmstead, R.; Morden, C. Ebb and flow of the chloroplast inverted repeat. Mol. Gen. Genet. 1996, 252, 195-206. [CrossRef] [PubMed]

34. Wang, R.-J.; Cheng, C.-L.; Chang, C.-C.; Wu, C.-L.; Su, T.-M.; Chaw, S.-M. Dynamics and evolution of the inverted repeat-large single copy junctions in the chloroplast genomes of monocots. BMC Evol. Biol. 2008, 8, 36. [CrossRef] [PubMed]

35. Peery, R. Understanding Angiosperm Genome Interactions and Evolution: Insights from Sacred Lotus (Nelumbo Nucifera) and the Carrot Family (Apiaceae). Ph.D. Thesis, University of Illinois at Urbana-Champaign, Champaign, IL, USA, 2015.

36. Khakhlova, O.; Bock, R. Elimination of deleterious mutations in plastid genomes by gene conversion. Plant J. 2006, 46, 85-94. [CrossRef] [PubMed] 
37. Moore, M.J.; Bell, C.D.; Soltis, P.S.; Soltis, D.E. Using plastid genome-scale data to resolve enigmatic relationships among basal angiosperms. Proc. Natl. Acad. Sci. USA 2007, 104, 19363-19368. [CrossRef] [PubMed]

38. Huang, Y.; Li, X.; Yang, Z.; Yang, C.; Yang, J.; Ji, Y. Analysis of complete chloroplast genome sequences improves phylogenetic resolution in Paris (Melanthiaceae). Front. Plant Sci. 2016, 7, 1797. [CrossRef] [PubMed]

39. Zhang, N.; Erickson, D.L.; Ramachandran, P.; Ottesen, A.R.; Timme, R.E.; Funk, V.A.; Luo, Y.; Handy, S.M. An analysis of Echinacea chloroplast genomes: Implications for future botanical identification. Sci. Rep. 2017, 7, 216. [CrossRef] [PubMed]

40. Potter, D.; Eriksson, T.; Evans, R.C.; Oh, S.; Smedmark, J.; Morgan, D.R.; Kerr, M.; Robertson, K.R.; Arsenault, M.; Dickinson, T.A. Phylogeny and classification of Rosaceae. Plant Syst. Evol. 2007, 266, 5-43. [CrossRef]

41. Eriksson, T.; Hibbs, M.S.; Yoder, A.D.; Delwiche, C.F.; Donoghue, M.J. The phylogeny of Rosoideae (Rosaceae) based on sequences of the internal transcribed spacers (ITS) of nuclear ribosomal DNA and the trnL/F region of chloroplast DNA. Int. J. Plant Sci. 2003, 164, 197-211. [CrossRef]

42. Jansen, R.K.; Cai, Z.; Raubeson, L.A.; Daniell, H.; Leebens-Mack, J.; Müller, K.F.; Guisinger-Bellian, M.; Haberle, R.C.; Hansen, A.K.; Chumley, T.W. Analysis of 81 genes from 64 plastid genomes resolves relationships in angiosperms and identifies genome-scale evolutionary patterns. Proc. Natl. Acad. Sci. USA 2007, 104, 19369-19374. [CrossRef] [PubMed]

43. Andrews, S.C. FastQC v0.11.3; Babraham Bioinformatics: Cambridge, MA, USA, 2015; Available online: http://www.bioinformatics.babraham.ac.uk/projects/fastqc/ (accessed on 20 December 2017).

44. Johnson, M.; Zaretskaya, I.; Raytselis, Y.; Merezhuk, Y.; McGinnis, S.; Madden, T.L. NCBI BLAST: A better web interface. Nucleic Acids Res. 2008, 36, W5-W9. [CrossRef] [PubMed]

45. Luo, R.; Liu, B.; Xie, Y.; Li, Z.; Huang, W.; Yuan, J.; He, G.; Chen, Y.; Pan, Q.; Liu, Y. SOAPdenovo2: An empirically improved memory-efficient short-read de novo assembler. Gigascience 2012, 1, 18. [CrossRef] [PubMed]

46. Boetzer, M.; Henkel, C.; Jansen, H.; Butler, D.; Pirovano, W. Scaffolding pre-assembled contigs using SSPACE. Bioinformatics 2011, 27, 578-579. [CrossRef] [PubMed]

47. Liu, C.; Shi, L.; Zhu, Y.; Chen, H.; Zhang, J.; Lin, X.; Guan, X. CpGAVAS, an integrated web server for the annotation, visualization, analysis, and GenBank submission of completely sequenced chloroplast genome sequences. BMC Genom. 2012, 13, 715. [CrossRef] [PubMed]

48. Schattner, P.; Brooks, A.N.; Lowe, T.M. The tRNAscan-SE, snoscan and snoGPS web servers for the detection of tRNAs and snoRNAs. Nucleic Acids Res. 2005, 33, W686-W689. [CrossRef] [PubMed]

49. Lowe, T.M.; Eddy, S.R. tRNAscan-SE: A program for improved detection of transfer RNA genes in genomic sequence. Nucleic Acids Res. 1997, 25, 955-964. [CrossRef] [PubMed]

50. Lohse, M.; Drechsel, O.; Bock, R. OrganellarGenomeDRAW (OGDRAW): A tool for the easy generation of high-quality custom graphical maps of plastid and mitochondrial genomes. Curr. Genet. 2007, 52, 267-274. [CrossRef] [PubMed]

51. Mayor, C.; Brudno, M.; Schwartz, J.R.; Poliakov, A.; Rubin, E.M.; Frazer, K.A.; Pachter, L.S.; Dubchak, I. VISTA: Visualizing global DNA sequence alignments of arbitrary length. Bioinformatics 2000, 16, 1046-1047. [CrossRef] [PubMed]

52. Frazer, K.A.; Pachter, L.; Poliakov, A.; Rubin, E.M.; Dubchak, I. VISTA: Computational tools for comparative genomics. Nucleic Acids Res. 2004, 32, W273-W279. [CrossRef] [PubMed]

53. Tamura, K.; Peterson, D.; Peterson, N.; Stecher, G.; Nei, M.; Kumar, S. MEGA5: Molecular evolutionary genetics analysis using maximum likelihood, evolutionary distance, and maximum parsimony methods. Mol. Biol. Evol. 2011, 28, 2731-2739. [CrossRef] [PubMed]

54. Yang, X.-M.; Sun, J.-T.; Xue, X.-F.; Zhu, W.-C.; Hong, X.-Y. Development and characterization of 18 novel EST-SSRs from the western flower thrips, Frankliniella occidentalis (Pergande). Int. J. Mol. Sci. 2012, 13, 2863-2876. [CrossRef] [PubMed]

55. Kurtz, S.; Choudhuri, J.V.; Ohlebusch, E.; Schleiermacher, C.; Stoye, J.; Giegerich, R. REPuter: The manifold applications of repeat analysis on a genomic scale. Nucleic Acids Res. 2001, 29, 4633-4642. [CrossRef] [PubMed] 
56. Salamone, I.; Govindarajulu, R.; Falk, S.; Parks, M.; Liston, A.; Ashman, T.L. Bioclimatic, ecological, and phenotypic intermediacy and high genetic admixture in a natural hybrid of octoploid strawberries. Am. J. Bot. 2013, 100, 939-950. [CrossRef] [PubMed]

57. Larkin, M.A.; Blackshields, G.; Brown, N.; Chenna, R.; McGettigan, P.A.; McWilliam, H.; Valentin, F.; Wallace, I.M.; Wilm, A.; Lopez, R. Clustal W and Clustal X version 2.0. Bioinformatics 2007, 23, 2947-2948. [CrossRef] [PubMed]

58. Swofford, D.L. PAUP*: Phylogenetic Analysis Using Parsimony ( ${ }^{*}$ and Other Methods); Version 4.0b10; Sinauer Associates: Sunderland, MA, USA, 2002.

Sample Availability: Sequences data of four Sanguisorba species (S. officinalis, S. filiformis, S. stipulata, and S. tenuifolia var. alba) are available from the authors.

(C) 2018 by the authors. Licensee MDPI, Basel, Switzerland. This article is an open access article distributed under the terms and conditions of the Creative Commons Attribution (CC BY) license (http://creativecommons.org/licenses/by/4.0/). 